\title{
PATRIMÔNIO HISTÓRICO E DESENVOLVIMENTO LOCAL: UMA REFLEXÃO DA (RE) PRODUÇÃO DO ESPAÇO URBANO NO BAIRRO FUNDINHO - UBERLÂNDIA (MG)
}

\author{
Suélem Marques de Oliveira ${ }^{1}$
}

\begin{abstract}
RESUMO
O Bairro Fundinho corresponde à área de formação inicial da cidade de Uberlândia, constituída entorno da antiga Igreja Matriz de Nossa Senhora do Carmo. Desde a sua gênese até os dias atuais, essa área considerada nobre tem sofrido diversas modificações em busca principalmente do desenvolvimento e da almejada modernidade. Este trabalho tem como objetivo traçar relações envolvendo o patrimônio histórico, o desenvolvimento local com a questão da (re) produção do espaço urbano e mostrar através de arquivos recentes e antigos cedidos pela Prefeitura Municipal de Uberlândia como essa cidade se estruturou apesar de alguns desafios ao longo do caminho. Analisar a (re) produção do espaço do bairro Fundinho desempenha um importante papel, pois ao analisar o contexto e os fatos históricos (através de entrevistas concedidas por moradores antigos), podemos compreender o porquê daquele lugar está organizado daquela forma e assim conseguimos descobrir como surgiram certos costumes e o motivo pelo qual ocorrem constantes mudanças naquele lugar. Avaliar uma paisagem, não diz respeito à simplesmente capturar uma imagem qualquer. Pois, enquanto um fenômeno vivido, a paisagem percebida é também construída a partir do olhar do observador, que muitas vezes lhe atribui não apenas o sentido da visão, como os demais sentidos, estabelecendo-se assim alguma significação entre o sujeito e o objeto.
\end{abstract}

PALAVRAS-CHAVE: Patrimônio Histórico. Desenvolvimento Local. Uberlândia (MG)

\section{HISTORICAL DEVELOPMENT AND LOCAL HERITAGE: A} REFLECTION OF THE (RE) PRODUCTION OF URBAN SPACE IN THE NEIGHBORHOOD FUNDINHO - UBERLÂNDIA (MG)

\footnotetext{
${ }^{1}$ Possui Licenciatura e Bacharelado em Geografia pela Universidade Federal de Uberlândia (2011), é Mestra em Geografia com ênfase em Estudos Ambientais pela Universidade Federal de Goiás Catalão (2014). Atualmente é professora de geografia na rede estadual de Minas Gerais e no Centro Federal de Educação Tecnológica de Minas Gerais (Araxá). E-mail: suelemarques@live.com
} 


\title{
Periódica Eletronica $\quad$ ISSN 1980-0827

\begin{abstract}
The Fundinho District is the area of initial formation of the city of Uberlândia, formed around the old Church of Our Lady of Mount Carmel. Since its genesis to the present day, this prime area has considered several modifications mainly in search of development and desired modernity. This paper aims to outline the relationships involving heritage, local development with the issue of (re) production of urban space and show through recent and ancient assigned by the Municipality of Uberlândia how this city was structured files despite some challenges to along the way. Analyze the (re) production of space Fundinho neighborhood plays an important role, because when analyzing the context and historical facts (through interviews given by former residents), we can understand why that place is organized and that way we can find out how well certain customs have arisen and why the constant changes occurring in that place. Assess a landscape, not just with respect to capture any image. For as a phenomenon experienced, perceived landscape is also built from the viewer's gaze, which often gives you not just the sense of sight, as the other senses, thus establishing any significance between the subject and the object.
\end{abstract}

KEY-WORDS: Heritage. Local Development. Uberlândia (MG)

\section{DESARROLLO HISTÓRICO Y PATRIMONIO LOCAL: UN REFLEJO DE LA (RE) PRODUCCIÓN DEL ESPACIO URBANO EN EL BARRIO FUNDINHO - UBERLÂNDIA (MG)}

\section{RESUMEN}

El Distrito Fundinho es el campo de la formación inicial de la ciudad de Uberlândia, formado alrededor de la antigua Iglesia de Nuestra Señora del Monte Carmelo. Desde su génesis hasta la actualidad, esta zona privilegiada ha considerado varias modificaciones, principalmente en la búsqueda del desarrollo y la modernidad deseada. Este trabajo tiene como objetivo describir las relaciones que involucran el patrimonio, el desarrollo local con el tema de la (re) producción del espacio urbano y mostrar a través de reciente y antigua asignado por la Municipalidad de Uberlândia cómo esta ciudad fue de archivos estructurados a pesar de algunos desafíos a a lo largo del camino. Analizar la (re) producción del espacio barrio Fundinho juega un papel importante, ya que al analizar el contexto y los hechos históricos (a través de entrevistas dadas por los antiguos residentes), podemos entender por qué ese lugar es organizado y de esa manera podemos saber qué tan bien ciertas costumbres han surgido y por qué los cambios constantes que ocurren en ese lugar. Evaluar un paisaje, no sólo con respecto a capturar cualquier imagen. Porque como un fenómeno experimentado, paisaje percibido también se construye a partir de la mirada del espectador, que a menudo no se da sólo el sentido de la vista, como los otros sentidos, estableciendo así un significado entre el sujeto y el objeto.

PALABRAS-CLAVE Patrimonio. Desarrollo Local. Uberlândia (MG) 


\section{INTRODUÇÃO}

O Bairro Fundinho corresponde à área de formação inicial da cidade de Uberlândia, constituída entorno da antiga Igreja Matriz de Nossa Senhora do Carmo. Desde a sua gênese até os dias atuais, essa área considerada nobre tem sofrido diversas modificações em busca principalmente do desenvolvimento e da almejada modernidade.

Este trabalho tem como objetivo traçar relações dessa história com a questão da (re) produção do espaço urbano a partir da perspectiva do materialismo histórico dialético e mostrar através de arquivos recentes e antigos cedidos pela Prefeitura Municipal de Uberlândia como essa cidade se estruturou apesar de alguns desafios ao longo do caminho.

A metodologia deste trabalho está baseada em análise de trabalhos que discorreram sobre a formação da cidade de Uberlândia, bem como o desenvolvimento do bairro Fundinho. Após a análise em livros e teses, tornou-se necessário a aplicação de entrevistas e questionários aos moradores mais antigos do local, moradores estes que enriqueceram o trabalho com as lembranças vividas por ele e por suas famílias. Foi uma experiência muito significante poder conhecer um pouco da história desses moradores, que trouxeram em cada fala, suas lembranças e saudade.

Analisamos também a paisagem do bairro Fundinho a partir dos tombamentos que foram realizados em busca da modernidade. Foi possível notar que, enquanto um fenômeno vivido, a paisagem percebida é também construída a partir do olhar do observador, que muitas vezes Ihe atribui não apenas o sentido da visão, como os demais sentidos, estabelecendo-se assim alguma significação entre o sujeito e o objeto. Ainda, com o objetivo de fazer uma apreciação ao atual uso do espaço, da memória e da estrutura arquitetônica daquele bairro, fizemos uma pequena crítica aos estabelecimentos que de forma pontual exclui a maioria da população por oferecer mercadorias e serviços direcionados apenas uma classe da sociedade. 


\section{HISTÓRICO DO BAIRRO FUNDINHO}

De acordo com o levantamento de Attux et al. (2008), a formação do bairro Fundinho está associada ao processo de produção do espaço de Uberlândia, pela qual se tornou o primeiro núcleo de habitação em meados de 1850. Sendo constituída no entorno da antiga Igreja Matriz de Nossa Senhora do Carmo (Figura 1).

Figura 1: Antiga Matriz de Nossa Senhora do Carmo, demolida em 1943.

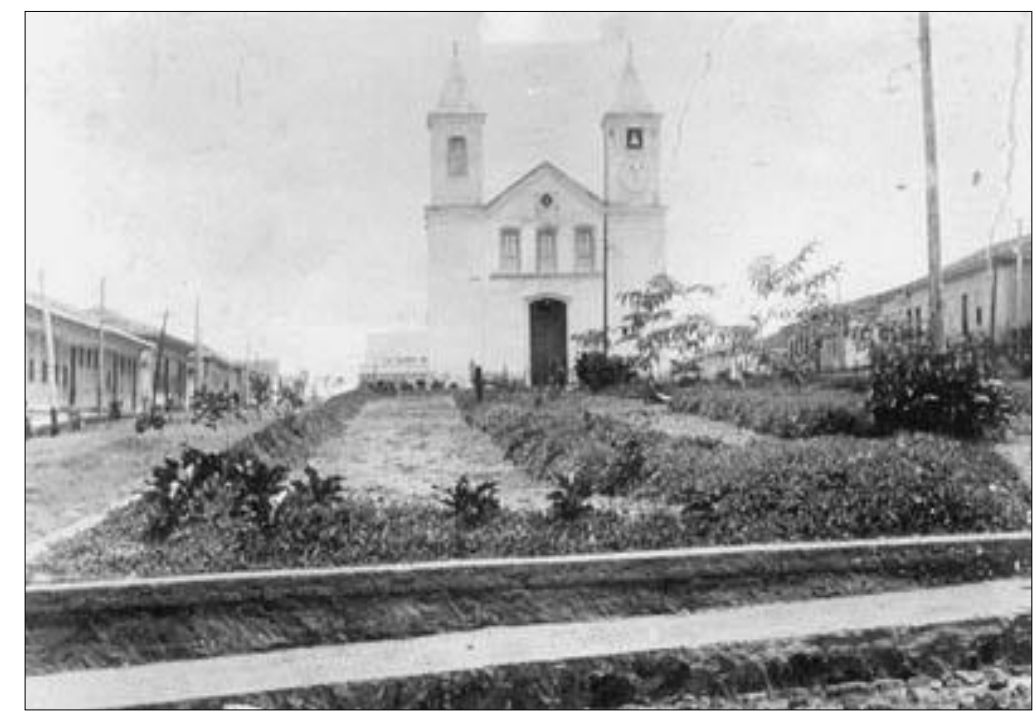

Fonte: Arquivo Público Municipal de Uberlândia.

Naquele momento a pecuária consolidava-se como importante atividade econômica e por isso exercia grande poder no Brasil. Com o passar do tempo foi ocupando extensas terras ao longo de todo território, e não foi diferente na região até então denominada Sertão da Farinha Podre.

O bairro Fundinho possui uma história que nos ajuda a compreender o processo de formação de Uberlândia, uma vez que, ele foi palco de grandes realizações que contribuem para o que vemos hoje consolidado. Segundo Soares (1995) esse espaço "contém especificidades, uma história própria e um conjunto de relações sociais, um espaço de memória, de formação de identidades e de práticas políticas".

A instalação da estação da estrada de ferro da Companhia Mogiana, em 1895, trouxe novas perspectivas de desenvolvimento para o arraial. Localizada a 
seis quilômetros de distância do Largo da Matriz, para fazer a ligação do antigo núcleo à Praça da Estação, foram abertas seis avenidas paralelas e ruas transversais, formando um tabuleiro regular. As ruas mais largas e os quarteirões regulares introduziram na vila novas formas de ordenamento urbano, contrastando com o antigo núcleo de ruas mais estreitas e longos quarteirões

A ferrovia propiciou o início do desenvolvimento econômico da cidade, logo fortalecido pela construção da ponte sobre o Rio Araguari e das estradas de rodagem, que ligavam a cidade às regiões interioranas de Goiás, Mato Grosso e São Paulo, consolidando, assim, Uberlândia como entreposto comercial.

O deslocamento das atividades comerciais para essa nova área de expansão, consolidada a partir de década de 1940, favoreceu, por algum tempo, a preservação das características originais do antigo núcleo, que aos poucos passou a ser identificado como Fundinho. Os imigrantes de origem européia, que chegaram com a estrada de ferro, substituíram a antiga mão de obra e impuseram novas técnicas, novos padrões de moradia e de socialização, identificados com o desenvolvimento almejado pela sociedade. A cidade viu a introdução de novos serviços públicos como a energia elétrica e 0 abastecimento de água potável; revestiu-se de grandes casarões decorados, de ruas arborizadas e jardins que deram nova fisionomia à sua paisagem (Figura 2).

Com a ampliação do comércio, da economia em geral e a implantação de eixos viários nessa região, tornou-se comum à construção de casas conforme a arquitetura moderna. Diante da excelente localização (próximo ao centro e aos principais pontos de procura) essa área passou a sofrer intensas especulações. Com o tempo as construções verticalizadas foram ganhando espaço e com isso toda uma estrutura e identidade daquela região que fora construída por muitos anos, submeteu-se a uma grande modificação para atender a essa nova organização do espaço. 
Figura 2: Arquitetura eclética do início do século XX no antigo Largo da Cavalhada, atual Praça Coronel Carneiro.

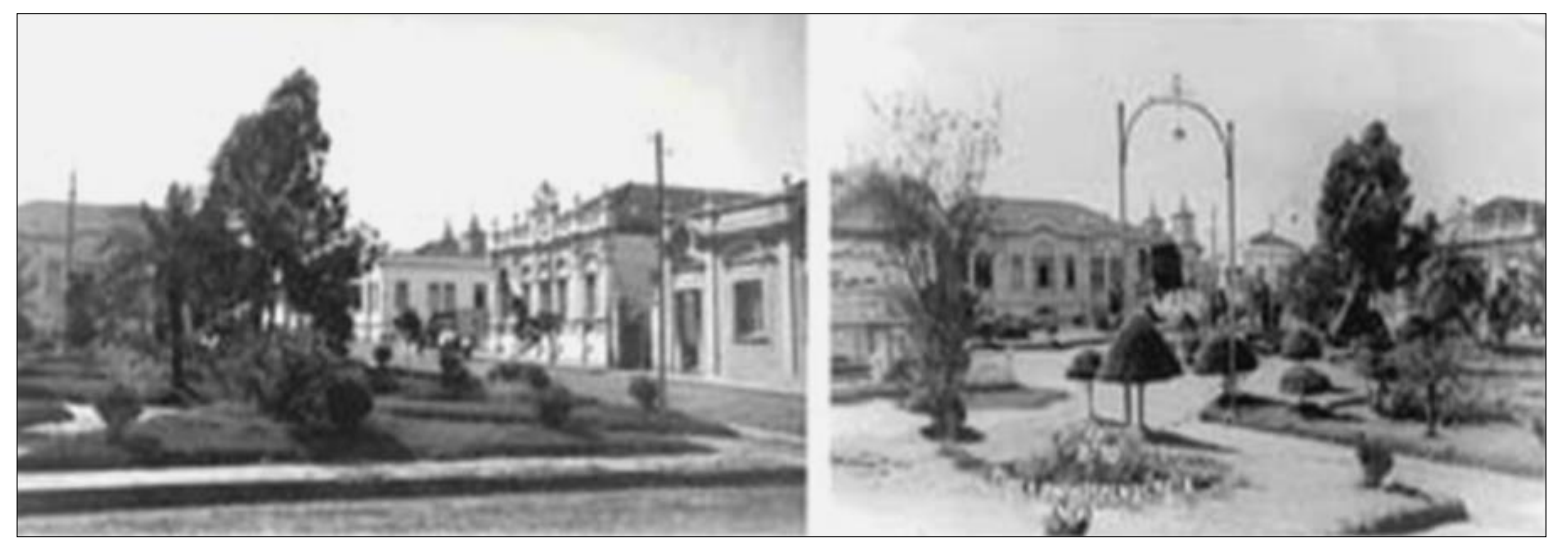

Fonte: Arquivo Público Municipal de Uberlândia.

A partir da década de 1960, com a crescente urbanização, as antigas casas do Bairro Fundinho foram reformadas ou substituídas por outras que empregavam novos materiais e técnicas, mas conservaram o uso residencial ou de serviço local. Já na década de 1970, o crescimento econômico e demográfico da cidade impôs um novo ritmo à construção, pressionando a substituição das antigas estruturas por novos edifícios, modernos e verticalizados, que rapidamente passaram a marcar a paisagem da cidade.

Neste momento, o bairro passa a sofrer forte especulação imobiliária, oferecendo-se como uma área de grande interesse para os novos investimentos imobiliários, atraídos por sua posição privilegiada junto ao centro, dando início a um intenso processo de verticalização e substituição de suas funções e estruturas originais (Figuras 3 e 4). 
Figuras 3 e 4: Paisagem do Fundinho e da Praça Clarimundo Carneiro (primeiro plano) e o do Centro de Uberlândia (segundo plano), na década de 1940 e atualmente.
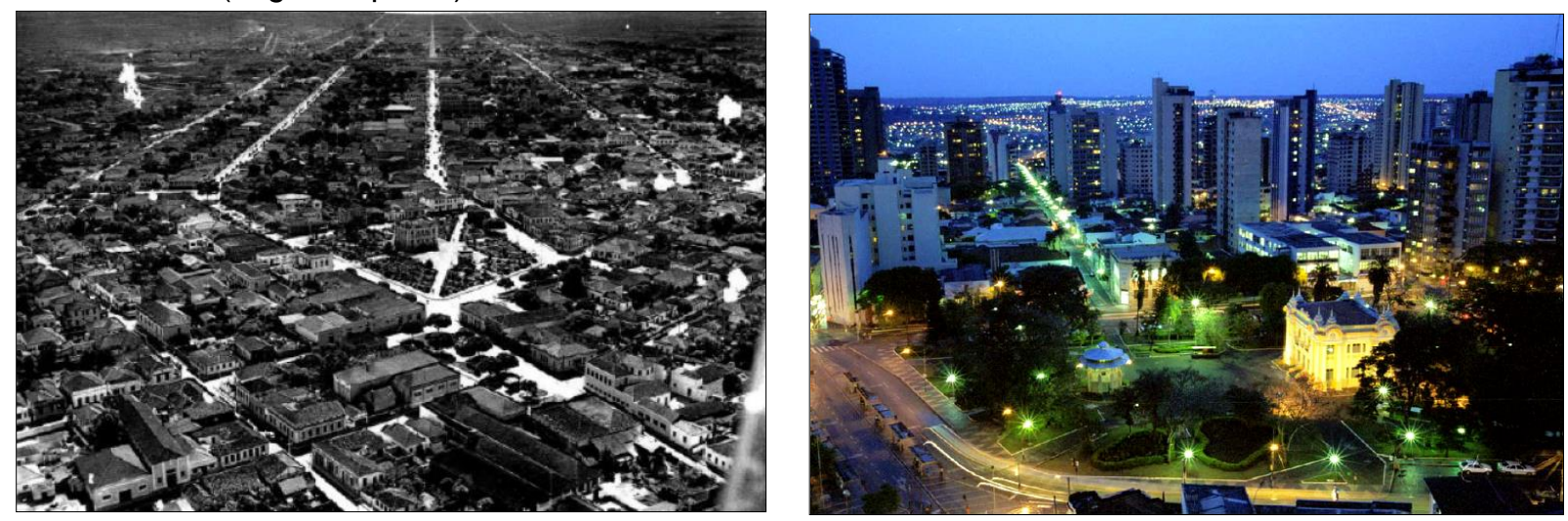

Fonte: Arquivo Público Municipal de Uberlândia / GOULART, 2006.

Aproveitando o cenário de forte especulação imobiliária que o bairro sofreu e ainda sofre nos dias atuais, abro um parêntese para demonstrar rapidamente como aquele espaço se reproduz diariamente em busca da valorização do capital. Isso acontece, porque segundo Singer (1978) "escolas, clínicas médicas e dentárias, salões de beleza, butiques, cinemas, etc., abandonam suas localizações e edificações obsoletas, pelo fato de oferecer instalações atraentes em locais preferenciais, tais como antigos bairros residenciais ou shopping centers, à sua exigente burguesia.

Nesse bairro nobre de Uberlândia, encontramos com facilidade lojas requintadas, com altos preços e uma clientela diferenciada. Essas lojas denominadas "butiques", segundo Singer (1978), localizam-se nos centros urbanos, devido à concentração de população rica.

Figuras 5 e 6: Butiques localizadas no bairro Fundinho
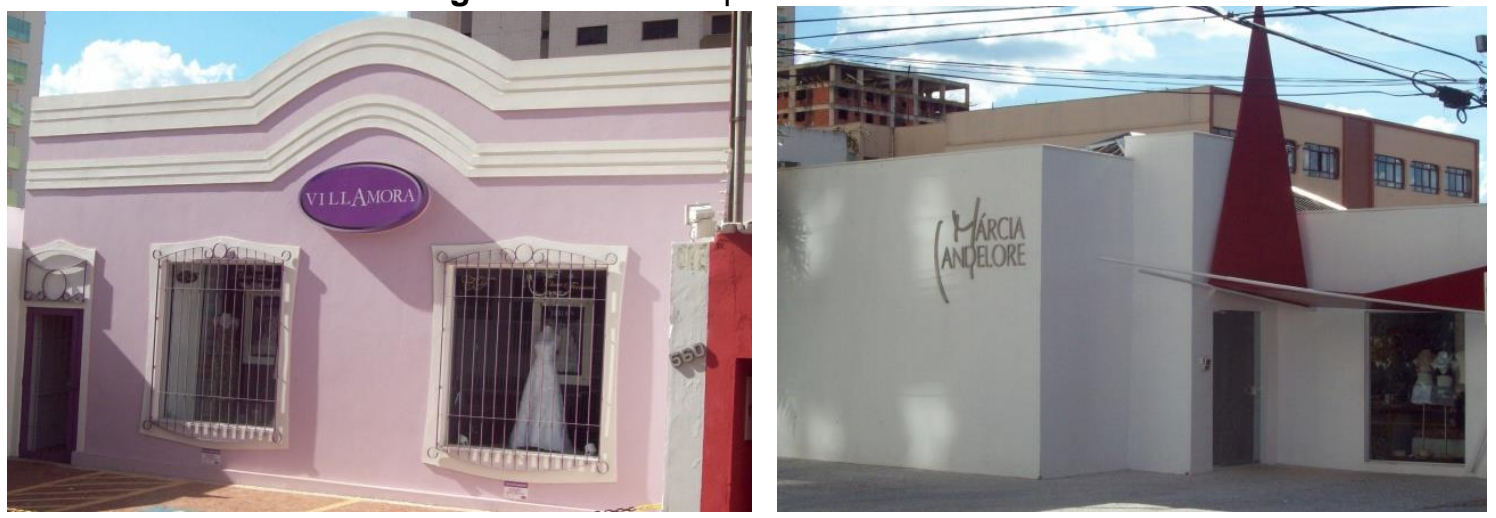

Fonte: OLIVEIRA, S. M 
Soares (1995) relata que esse pequeno grupo, composto por uma população rica, homogênea e coesa, acaba exercendo um enorme poder na população e na cidade, e uma vez que essa minoria está no controle, ela mantém o seu poderio e sua hegemonia nas decisões políticas e econômicas.

Para chegarmos ao almejado nível de desenvolvimento que perpetuou toda a história do bairro Fundinho, ainda na década de 1980, a preocupação com a preservação da memória da cidade, traduziu-se nos tombamentos de alguns imóveis do bairro. Dentre todos os imóveis atualmente tombados em Uberlândia, quatro tiveram seu tombamento durante esta década, são eles (Figuras 7, 8, 9, 10, 11, 12, 13, 14):
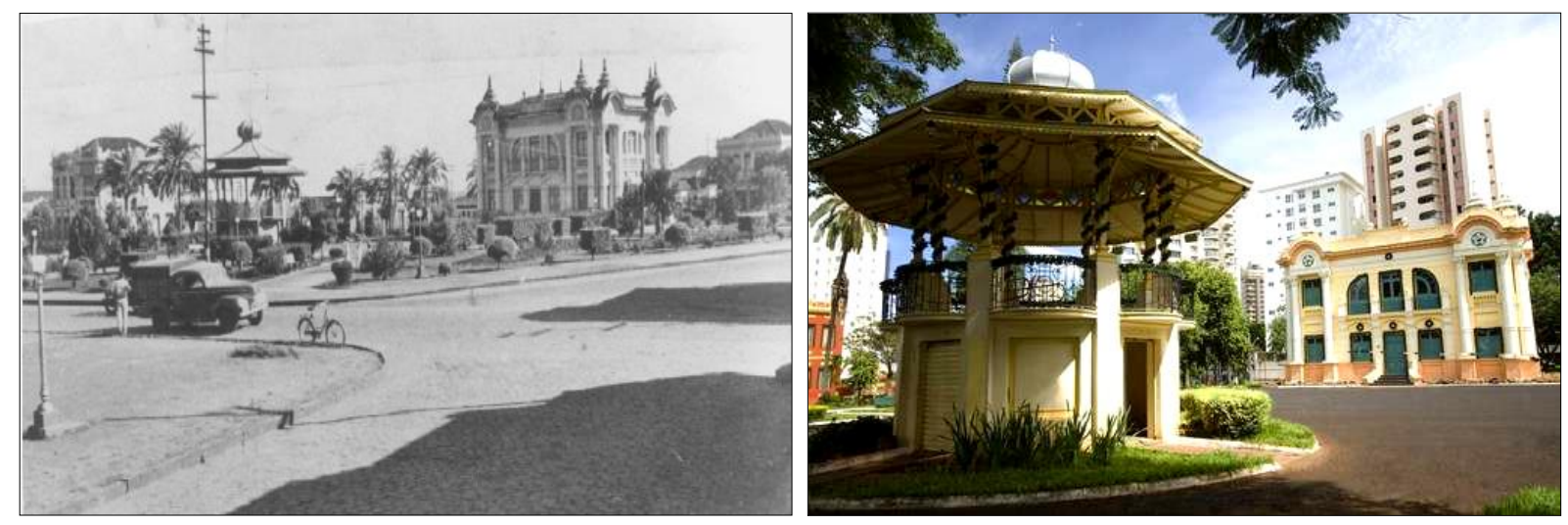

Figuras 7 e 8: Conjunto Praça Clarimundo Carneiro (antiga Praça Antônio Carlos), Edifício da Câmara Municipal e Coreto, na década de 1940 e atualmente. Fonte: Arquivo Público Municipal de Uberlândia / OLIVEIRA, S.M
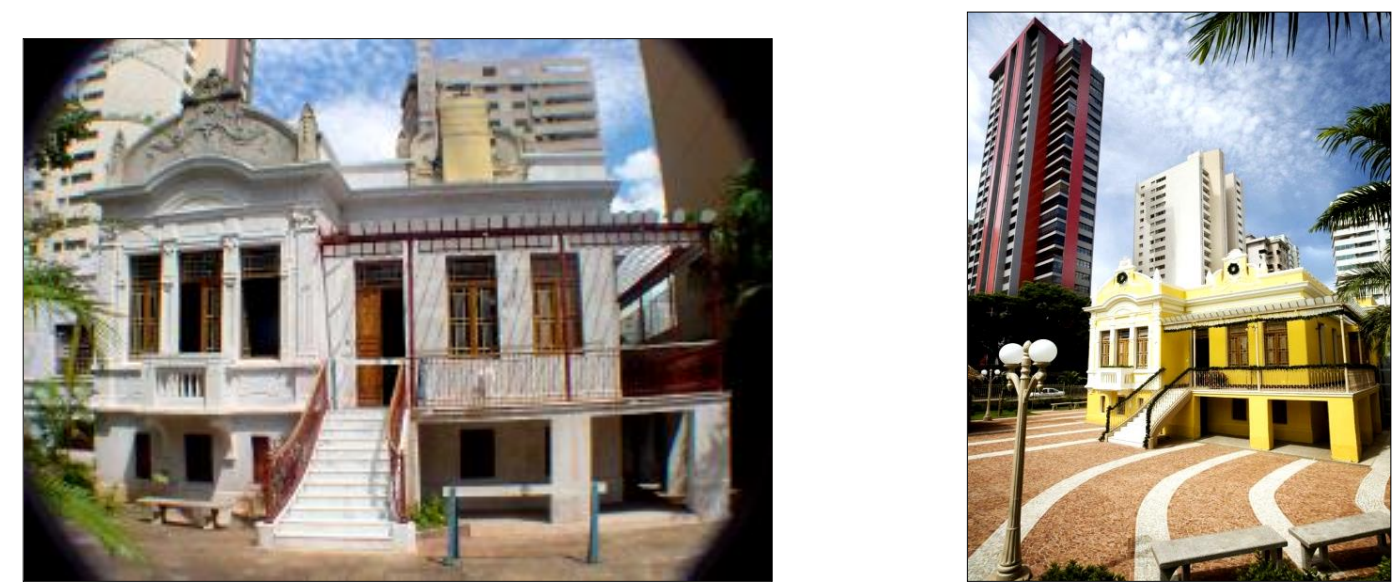

Figuras 9 e 10: Casa da Cultura em 2004, antes de passar por reforma, e atualmente. Fonte: GOULART, 2006 / OLIVEIRA, S. M. 
Figuras 11 e 12: Antiga Companhia de Força e Luz de Uberabinha (1929), atual Oficina Cultural de Uberlândia.
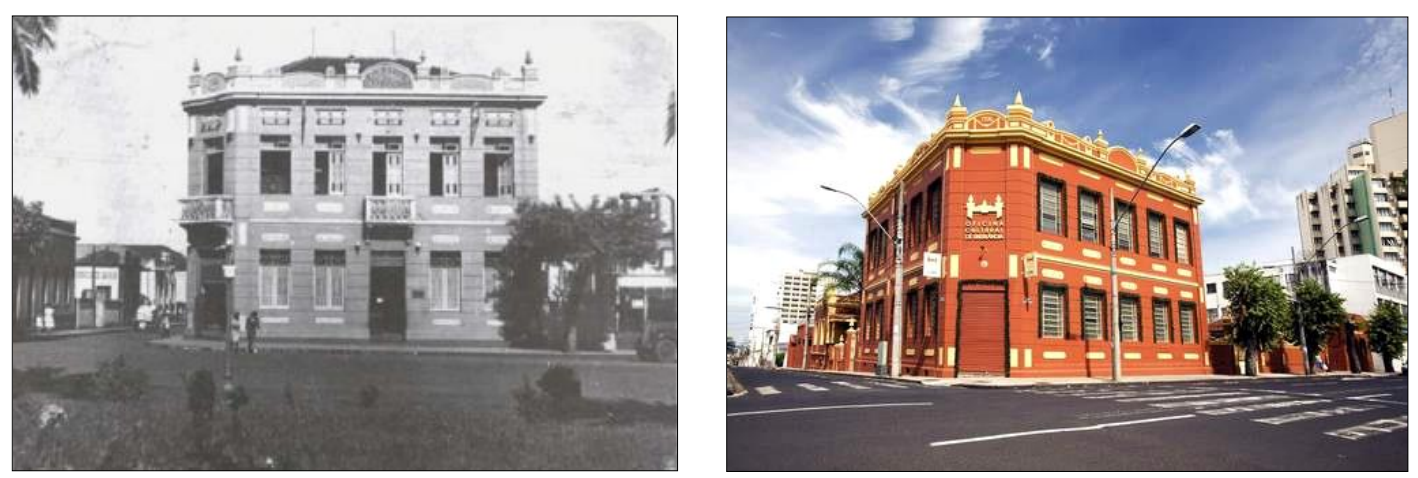

Fonte: Arquivo Público Municipal de Uberlândia / OLIVEIRA, S.M.

Figuras 13 e 14: Igreja Nossa Senhora do Rosário em sua inauguração na década de 1930 e atualmente.
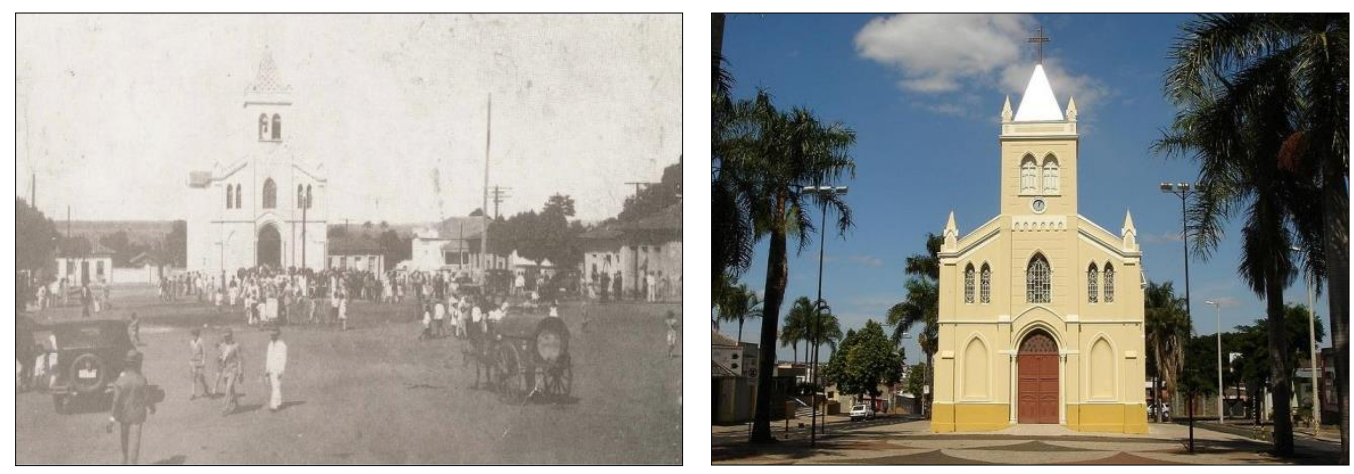

Fonte: Arquivo Público Municipal de Uberlândia

\section{CONSTASTAÇÕES EM CAMPO}

Em busca dos sujeitos que participam das paisagens urbanas e tem sua relação de pertencimento com o lugar, no caso o Bairro Fundinho, foi realizado entrevistas como forma de complementar o trabalho. Nelas, buscou-se demonstrar a importância do bairro em relação ao patrimônio publico municipal e a vida cotidiana e sentimental de seus moradores mais antigos.

Existem no bairro, alguns moradores que presenciaram toda a metamorfose de sua paisagem constituinte, conservando vários bens materiais e imateriais desse 
processo histórico, que o Fundinho vem passando desde o início do surgimento da cidade.

Assim com o desenvolvimento e o processo de modernização do bairro, podese verificar que a cidade de Uberlândia sempre teve a preocupação em estar buscando o novo, o moderno, de forma que não se sentisse em um processo de urbanização atrasado. Fato perceptível tanto nos modernos edifícios, com até em seus antigos casarões compostos por vários cômodos, materiais importados, banheiros internos, entre outras características infra-estruturais que para época em que foram construídos simbolizavam poder e status. Isto foi bem perceptível na fala da entrevistada 1, que trabalha com esta questão de preservação do patrimônio cultural da cidade:

"[...] no inicio da construção de Uberlândia, com as casas ainda novas, nos jornais da época era normal que saíssem publicações perguntando o que aquela casa em determinado local do bairro ainda estava fazendo ali, que ela já havia cumprido seu papel na história da cidade e passado da hora de ser derrubada para dar lugar a uma nova construção que trouxesse o desenvolvimento, $o$ ar de modernidade para a cidade. $E$ isso ocorreu desde $o$ momento em que a cidade era apenas um arraial com 13 anos, quando já havia a divisão entre cidade velha e cidade nova, quando a cidade era apenas um lugar de passagem das mercadorias provenientes do estado de São Paulo em direção ao estado de Goiás. Mas mesmo assim em um arraial pouco habitado existia a necessidade em estar demonstrando todo esse luxo. Com a vinda da estrada de ferro Mogiana a cidade passa a crescer e há um crescimento demográfico, neste momento, um engenheiro é contratado pela ferrovia e faz o traçado de 6 avenidas principais (Cesário Alvin, Floriano Peixoto, Afonso Pena, João Pinheiro, Cipriano Del Fávero e Getúlio Vargas), cortadas por ruas em traçado retilíneo que ligavam a cidade a estação ferroviária. Na década de 1930 há relatos do crescimento da cidade e da necessidade de novas construções, onde quem lesse noticias nos jornais até pensava que se tratava de São Paulo..."

Porém, diante de todo esse discurso de modernidade, também houve a preocupação por parte de alguns em se preservar o patrimônio cultural da cidade, sejam os materiais (casas, propriedades, objetos) ou imateriais (as festas e tradições que pertencem àquele povo ou sociedade, no caso de Uberlândia, o Congado). 
Sobre a preservação do patrimônio cultural, o entrevistado explicou que seu tombamento pode ser realizado de duas formas: por meio do pedido realizado por um grupo social ou pela comunidade, onde há a procedência de toda uma ação burocrática; e por meio do decreto de uma lei por parte de algum representante público, por exemplo, o caso da vereadora Liza Prado na cidade de Uberlândia que tombou o Mercado Municipal e a árvore característica da região localizada na frente deste. Em relação à preservação do patrimônio cultural a entrevistada 1 destacou os seguintes aspectos:

"[...] para a ocorrência da preservação do patrimônio cultural é necessário que a população tenha consciência da importância que ele representa para ela, do que ele simboliza, é necessário que ela se aproprie daquele bem. A cidade de Uberlândia em si, não possui um símbolo próprio, pois sempre foi um lugar de passagem. Atualmente a Casa da Cultura trabalha com os alunos da Escola Estadual de Uberlândia e da Escola Estadual Dr. Duarte Pimentel, buscando conscientizar os alunos desde pequenos da importância histórica e da beleza arquitetônica do prédio onde eles estudam. Culturalmente, a cidade não traz a necessidade de se preservar e conservar, visto que ela sempre utilizou do discurso de se derrubar o velho para dar lugar ao moderno. Um exemplo disso é o velho prédio Fórum, que a imprensa tratava todo dia como um imóvel caindo aos pedaços, uma ameaça à segurança da população, mas também como não achar isso ao ver as plantas do novo prédio que seria construído. Quer coisa mais moderna para a época, do que aquele prédio de concreto, que conta até com estrutura para suportar terremotos. $E$ isso, vem desde o surgimento da cidade, pois esta no final do século XIX e inicio do século XX não era ponto estratégico, a Estrada Salineira sim, mas apenas um ponto de passagem. Enfim, não é fácil fazer a preservação do patrimônio histórico da cidade, pois na consciência das pessoas é mais fácil sempre estar derrubando o velho e construindo o novo, o moderno, e assim demonstrar status e poder..."

Em outras conversas, constatou-se a identificação dos entrevistados com aquele lugar. Em vários momentos de suas falas, percebe-se que embora a paisagem esteja quase que em sua plenitude modificada, eles utilizam dos cenários atuais como referência para falar dos passados, sempre apontando em uma direção.

O entrevistado 2, um senhor que viveu no bairro durante quase 50 anos, descreveu algumas particularidades das paisagens que fizeram parte de sua infância:

"[...] naquela época, os moradores da zona rural se direcionavam aos armazéns do senhor Coronel Severiano, no antigo Largo da Cavalhada, e do 
senhor Custodio Pereira, na antiga Praça da Matriz de Nossa Senhora do Carmo. Nesses locais, havia um intenso movimento comercial e era onde as pessoas se reunião, onde recebiam as tropas de carros de bois que traziam mercadorias para serem comercializadas na cidade, mercadorias essas que variavam desde alimentos até armamentos e munições."

Pôde-se perceber, durante toda sua entrevista, o seu saudosismo e pertencimento com o bairro, pois em vários momentos ele se refere a uma época que jamais voltará, expressando a saudade dos velhos hábitos e das relações sociais que construiu, observando que ainda há uma parcela remanescente desses moradores. $O$ entrevistado 2, ainda relatou sobre o processo de modernização do bairro, dizendo que isso não o incomodava por fazer parte do desenvolvimento da cidade. Porém lamenta a perda da referência de alguns imóveis que foram demolidos para dar lugar a prédios e casas de comercio, pois durante a sua explanação ele indicava os imóveis e falava sobre o que existia antes naquele local. Ele, ainda, fez questão de contar das travessuras que aprontava quando criança:

"[...] quando criança eu possuía muitos amigos, era coroinha da Matriz de Nossa Senhora do Carmo. Hoje eu não moro mais aqui no bairro, moro no Bairro Brasil, mas sempre venho aqui para rever e conversar com velhos amigos..."'[...] a Matriz de Nossa Senhora do Carmo, possuía suas torres e numa delas havia o sino, que eu tocava na época que fui coroinha um relógio bem grande se vidro. Então, quando eu era menino, pegava meu estilingue e me escondia para não ser pego, aí quando o relógio andava para a esquerda eu ativara uma pedra e o adiantava ou, o contrário, quando ele descia, eu o atrasava. Um dia o padre me viu enquanto eu fazia isto, aí me pegou pela orelha e me levou até papai, falando o que eu estava aprontando..."

Esse tipo de relato serve para demonstrar que embora a funcionalidade dos espaços que formam o Bairro Fundinho, muitas vezes, tenha permanecido a mesma, principalmente no seu caráter comercial; as relações das pessoas com estes não, pois hoje dificilmente se estabelece relações sociais como as da infância e adolescência de pessoas como o entrevistado 2.

Por fim, a terceira entrevistada é uma senhora de 94 anos que reside no bairro desde a sua infância ali, na mesma residência, e é filha de uma das figuras presentes na história de Uberlândia. 
"[...] papai era um homem muito bom, ele era proprietário de algumas imóveis no bairro, como o antigo Teatro São Pedro e o comércio, onde se vendia todos os tipos de mercadorias. A cidade era uma parada de tropeiros, viajantes que paravam aqui para se pousar e se abastecerem..."

Esta entrevistada, mais uma vez, relata sobre a proximidade existente entre as pessoas que residiam ali no passado e as paisagens que eram encontradas. Questionada sobre o que a incomodava sobre a modernização e evolução do bairro, ela respondeu que não havia feito nada de diferente para adaptado às mudanças, porém falou da falta que certas coisas faziam, por exemplo, a Matriz de Nossa Senhora do Carmo:

"[...]não, não incomodo não. Eu fui me adaptando a medida que o bairro foi mudando... Uma coisa que eu sinto falta é da Igreja! Desde pequena, eu aprendi e gostava muito de ir lá, acho que não precisava ter derrubado ela... Gosto de ir a missa todos os dias e sem a lgreja aqui, passei a freqüentar a Catedral de Santa Terezinha, todos os dias o motorista me leva."

Um momento marcante desta entrevista foi quando questionamos a entrevistada 3 quanto a uma imagem adquirida com a primeira entrevistada, que se referia à casa comercial de seu pai, ainda durante a primeira metade do século XX (Figuras 15 e 16). Emocionada e com poucas palavras, ela refletiu algum tempo sobre a imagem tentando nos fazer entender como era aquela paisagem diante da casa reformada, e posteriormente nos mostrando várias fotos do seu arquivo pessoal.

Figuras 15 e 16: Imagem da casa comercial pertencente ao pai da entrevistada 3, no início da formação de Uberlândia, e a sua atual aparência.

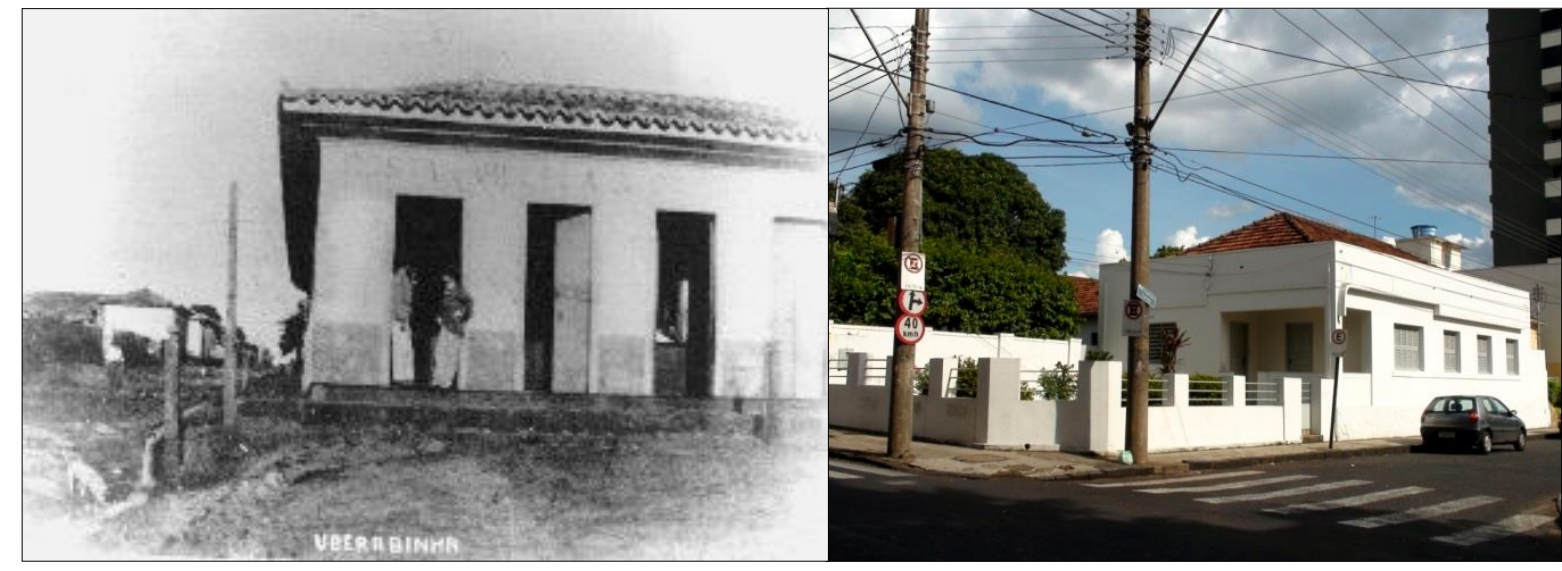

Fonte: Arquivo Público Municipal de Uberlândia 
Contudo a partir da visão de uma pessoa que trabalha com processo de formação histórica de Uberlândia e da perspectiva daqueles que passaram muitos anos de suas vidas, vivenciando e se adaptando às transformações sofridas no Bairro Fundinho, percebe-se a importância de se preservar aquilo que tenha algum significado diante da história daquele local. Porém, ressaltando a necessidade da comunidade se apropriar daquele bem como algo importante, porque, se não, não haverá sentido a sua preservação.

\section{CONSIDERAÇÕES FINAIS}

Como dito por Corrêa (2006), "a cidade é uma reconstrução da realidade, elaborada e reelaborada por indivíduos e grupos sociais a partir de práticas e experiências". E com a realização deste trabalho, a partir das paisagens urbanas encontradas e a forma como elas foram abordadas nas entrevistas, foi possível perceber a veracidade dessa afirmação.

Analisar a (re) produção do espaço do bairro Fundinho desempenha um importante papel, pois ao analisar o contexto fatos históricos, podemos compreender o porquê daquele lugar está organizado daquela forma e assim conseguimos descobrir como surgiram certos costumes e o motivo pelo qual ocorrem constantes mudanças naquele lugar.

Através das entrevistas, podemos ressaltar como resultado que avaliar uma paisagem, não diz respeito à simplesmente capturar uma imagem qualquer. Pois, enquanto um fenômeno vivido, a paisagem percebida é também construída a partir do olhar do observador, que muitas vezes lhe atribui não apenas o sentido da visão, como os demais sentidos, estabelecendo-se assim alguma significação entre o sujeito e o objeto. Observamos notoriamente durante as entrevistas, que os sujeitos ficaram emocionados por lembrar-se de momentos da sua vida com suas famílias e amigos.

Por isso o discurso da entrevistada 1, que para se preservar é necessário que o indivíduo e a comunidade se apropriem daquilo julgado importante para a histórica 
de um determinado local, como para sua própria história. Ou dos outros dois entrevistados, que durante toda a descrição da paisagem em que cresceram e hoje completamente modificada, sempre apresentaram seus sentimentos em relação àquele lugar: sua identificação, seu pertencimento e sua significação.

Dessa forma, a realização deste trabalho foi de grande proveito para a percepção da geograficidade da área de estudo, ou seja, das relações humanas com os espaços, paisagens e lugares ali presentes e demonstrou através das entrevistas que o lugar nesse sentido está carregado de sentimentos, emoções e que o indivíduo através das suas experiências carrega um vínculo muito maior que o material e concreto, para a maior parte dos entrevistados, o bairro Fundinho faz parte da sua vida. Hoje, da maneira como é modificado no bairro, o que é levado em conta é que se trata de um bairro nobre, carregado de história, mas que as lojas denominadas "boutiques" procuram reconhecimento e status, deixando a memória um pouco de lado e preocupando apenas na melhor maneira de se enquadrar ao sistema.

\section{REFERÊNCIAS BIBLIOGRÁFICAS}

ATTUX, D. E. et al. Fundinho: um bairro histórico para Uberlândia - inventário e diretrizes especiais de uso e ocupação do solo. In: Fórum e Patrimônio, v. 2, n. 1, 2008.

CARLOS, Ana Fani Alessandri. A (re) produção do espaço urbano. 1ª ed. São Paulo: Edusp, 1994.

CORRÊA, R. L. O urbano e a cultura: alguns estudos. In: CORRÊA, R. L; ROSENDAHL, Z. (Org.)

Cultura, espaço e o urbano. Rio de Janeiro: EdUERJ, 2006. p. 141-165.

CORRÊA, R. L; ROSENDAHL, Z. Cultura, espaço e o urbano: uma introdução. In: CORRÊA, R. L; ROSENDAHL, Z. (Org.) Cultura, espaço e o urbano. Rio de Janeiro: EdUERJ, 2006. p. 9-12.

RAMIRES, Júlio C. L. A Verticalização Do Espaço Urbano De Uberlândia: Uma Análise Da

Produção E Consumo Da Habitação. São Paulo: Faculdade de Filosofia Letras e Ciências Humanas, Universidade de São Paulo, 1998. (Tese, Doutorado em Geografia Humana).

SINGER, P. O uso do solo urbano na economia capitalista. São Paulo: Alfa-Omega. 1982. 31p.

SOARES, B. R. Uberlândia: da Cidade Jardim ao Portal do Cerrado. Tese (Doutorado em Geografia) - Departamento de Geografia, Universidade de São Paulo, São Paulo, 1995. 347 p. 